\title{
I Am Ocean: Expanding the Narrative of Ocean Science Through Inclusive Storytelling
}

\author{
Gianna M. Savoie ${ }^{1,2 *}$ \\ ${ }^{1}$ Centre for Science Communication, University of Otago, Dunedin, New Zealand, ${ }^{2}$ Ocean Media Institute, Bozeman, MT, \\ United States
}

Keywords: science, ocean, indigenous, filmmaking, communication, storytelling, narrative, media

\section{INTRODUCTION}

Over the past 20 years of my career, writing and producing science and natural history content for broadcasters including PBS/NATURE, National Geographic, Discovery and the BBC, I have served to tell another's story, whether human, animal or ecosystem. I embraced "narrative ownership" as a dictum of my field as it is always the writer, director, producer who asserts their signature on a story. Methodologically, the study of narrative ownership begins with the idea that narrative is interactive; it is about a relationship between tellers and hearers (De Fina and Georgakopoulou, 2011). The problem is that the vast majority of "the tellers" of science and natural history videos (especially those of ocean films) are predominantly white, and the stories told are from a Western scientific perspective. The relationship the storytellers have formed with their "hearers" is thus based upon that limited scope.

There is a wealth of scholarship on the lack of diversity in the sciences (e.g., Tallis and Lubchenco, 2014; Taylor, 2014; Green et al., 2015; Arismendi and Penaluna, 2016; Smith et al., 2017) and this extends to its communication, especially in the realm of ocean science and media. Arismendi and Penaluna (2016) stated, "Because diversity has been systematically underrepresented, we likely need to consider additional ways to systematically include it." This article explores my efforts to address this need via the establishment of the Ocean Media Institute (www.oceanmediainstitute.org), a global media collective that brings together diverse voices to create and distribute innovative online videos that promote ocean literacy. Through OMI, we have developed our flagship online series, $I$ Am Ocean, which casts a spotlight on the health of the world's oceans through short video postcards by those we rarely hear from, but are intimately tied to each ebb and flow. Combining the quest for new knowledge that is embedded in modern science and pairing it with the personal stories of those who have direct and historical knowledge of a place or system is at the heart of our work in providing a platform for indigenous and otherwise underrepresented voices to share their stories of ocean science and conservation from their perspective.

\section{FILLING THE HOLES IN THE SCIENCE WITH THE WHOLE OF THE STORY}

Accepted: 21 August 2020

Published: 06 October 2020

Citation:

Savoie GM (2020) I Am Ocean: Expanding the Narrative of Ocean

Science Through Inclusive Storytelling.

Front. Commun. 5:577913.

doi: $10.3389 / f c o m m .2020 .577913$

Science offers evidentiary truths about the workings of our world through its utility and function. But without story, science can fail to connect in a meaningful way. It is the narrative that provides science with its power. The explosion of online media in recent years has caused some scholars to argue that we are in an "Unlikely Golden Age" of production in terms of both quantity and quality of science and environmental storytelling (Hayden and Check Hayden, 2018). In terms of those stories being representative of diverse voices, however, that argument falls short. 
There's a perception within the Academy that Indigenous knowledge is "less than" and not as privileged as the Western way of understanding the world. "There is an immense challenge of proving to the scientific community that Indigenous knowledge is just as important as western science because the barriers to inclusive science are embedded in what is framed as science" (Rowe, 2017). Many western scientists and academics generally distinguish between scientific knowledge and Indigenous knowledge by claiming science is universal whereas Indigenous knowledge relates only to native people and their understanding of the world. It is time to look at these as complimentary rather than competing ideas. Indigenous knowledge can feed science in ways that can enable us to appreciate the world in a deeper and more holistic way. And when it comes to moving the needle, drawing upon multiple types of knowledge (e.g., Indigenous knowledge, local knowledge, science-based knowledge) strengthens the evidence-base for policy advice, decision making and environmental management (Alexander et al., 2019). Science communication practitioners must recognize this and expand participation in the narrative in order to engage the voices that are integral to the whole of the science. Only then can we reshape communicative relationships and move away from conceptualizations of science and society as separate and distinct from each other (Bucchi, 2016).

Effective science communication is not simply a oneway transmission of data, but rather a process that requires interpretation by the layperson in which their own history, personal beliefs and value sets-the architecture of culture-are embedded. When science is embedded in a contextual approach such as storycraft, it contributes to the critical task of developing an informed citizenship; a process that enables the public to engage with and act upon evidence relating to complex, futurefocused issues (Hipkins et al., 2014).

We tend to consider science from a western perspective in terms of objective, empirical, evidence-based information. Science communication, on the other hand, tends to be viewed as subjective, opinion-based, and value-laden. Objectivity and subjectivity are often viewed as antithetical, but this is a binary that won't survive the twenty-first century because science without the argument for it is meaningless. Our online video series, I Am Ocean is a call to rethink this binary and look at the places where science and culture overlap, where objectivity and subjectivity entwine, where western and Indigenous approaches mingle. In that shared space resides "narrative responsibility" the ethos inherent to both science and science communication to relay the science in a way that is factual, accessible and inclusive so that it that benefits all society.

\section{DISRUPTING NARRATIVE OWNERSHIP}

Over the past three decades, the subject of narrative has grown more prominent in the science communication discourse (Norris et al., 2005; Avraamidou and Osborne, 2009; Dahlstrom, 2014). Not only does the use of narratives help public audiences understand complex and abstract science issues, but it also makes the science easier to remember and process relative to traditional forms of scientific communication, such as lists, graphs, and figures (Dahlstrom, 2014). Yet, overwhelming disregard of diverse and indigenous perspectives in stories of science has created an incomplete narrative, reflecting a broad pattern of underrepresenting their importance. Viewers of online media about the ocean have been primarily on the receiving end of narratives that have been exposed to us through the lens of others-predominantly those of white European descent (myself included). Narratives are fundamental to how we perform our identities in relationships with others in that they both share and shape interactants' perspectives on the world, and notably, they are not value-neutral (Peterson and Garner, 2019). The minute we, as creators of online video content write a line or point a camera in a direction to record an event, we have made an editorial choice that affects and alters the relationship between viewer and subject. No matter how scientifically accurate the information, narrative ownership grants the architect of that story the liberty to construct, destroy and reconfigure it to suit the storyteller's objective through the filter of their own experience, history and value system-and often with the smack of appropriation.

Take the issue of climate change for example. We have all seen online videos overwrought with statistics and coupled with images of flooded homes of the "victims." Though Pacific Islanders are often seen as "the face" of climate change, they are seldom heard as "the voice" as they are least likely to be involved in meaningful climate adaptation discussions and rarely have narrative control of their own story, despite being most directly impacted (Mcleod et al., 2018). Too often, even the most wellintentioned filmmakers have entered a community to tell other people's stories, usually those in a vulnerable position, and slipped away without ever giving community members an opportunity to contribute (Rutherford, 2004). This can be damaging to capacity building as it may leave people they are trying to "help" feeling used, frustrated, and further disenfranchised.

\section{CRAFTING A COLLECTIVE NARRATIVE}

In coastal regions around the world, environmental health is interlaced with cultural health and when one erodes, so does the other. I Am Ocean offers a participatory experience for people living in communities perched precariously on the cusp of colossal change to candidly share their views about their ocean environment. Drawing on the power of their own voice, participants provide a glimpse into life in their region and their personal connection to the ocean as only they can. Whether a Bajao fisherman in the Philippines who is adopting new approaches to feed his family, a cultural leader in Hawaii whose ocean stewardship originates at the summit of Mauna Kea, or an Unangan community in the Pribilof Islands who are tackling the effects of marine debris, each contributor not only challenges assumptions about what science looks like, but what its voice sounds like. Our aim, however, is not to "give people a voice" - a phrase laced with arrogance as it assumes lack of agency by participants. Rather, we strive to turn the teller and hearer dynamic on its head. Instead of "telling" stories about the ocean, 
we start by listening to those who have intimate knowledge and experience with it and then provide a platform so that others may hear and learn from them. By refraining from inserting our own voice, values or belief systems into the videos, we allow for a more holistic story to emerge.

While there is a growing body of research on documentary filmmaking, relatively little is known about the participant's experience of documentary production (Nash, 2012). Our goal is to make this process transparent by shifting narrative agency to our participant storytellers. By providing free media training, they learn technical skills to pay it forward and also take an active part in the direction of the production, deciding where, when, what, and how the pieces are filmed.

The videos created are shared online via our global partner network as well as given back to the communities so they may share them freely and openly. As we embrace an open distribution model, it is impossible to calculate an accurate view count, but we estimate views in the millions as they are distributed to over a million teachers across the United States through PBS Learning Media, have been viewed hundreds of thousands of times via our own website and social media outlets, and have been screened and won awards at 21 international film festivals to date. In order to gauge our level of impact, we have begun collating workshop participant and viewer feedback.

\section{CONCLUSION}

The story of the ocean is multi-faceted and in constant motion. We have constructed a relationship with it through shifts in imagination, shifts in focus, shifts in culture, shifts in ways of seeing, of knowing, of understanding. Despite increasing attention to issues of diversity and inclusion, science still largely reflects and promotes the interests of a privileged minority (Adams et al., 2015; McCoy and Rodricks, 2015; Gill, 2018), as does its manifestation in visual media. In today's digital age, it is time to disrupt the notion of narrative ownership and shift toward a collective narrative whereby we as filmmakers and science communicators relinquish our claim on the story and invite others to participate in a shared narrative. Doing so honors each voice of the storyteller, allows the story to expand, and makes it possible to relay lessons across societal lines.

Creating a shift in the way our ocean stories are told means a collective shift in the approach to ocean science, itself. To tell an inclusive story demands a broadened vision great enough to seek out and invite the perspectives that have been neglected, removed or absorbed by others (Smith, 2017). This does not mean replacing one type of knowledge with another, but using them in concert to fortify the foundation of meaning.

\section{REFERENCES}

Adams, G., Dobles, I., Gómez, L. H., Kurtiş, T., and Molina, L. E. (2015). Decolonizing psychological science: introduction to the special thematic section. J. Soc. Politic. Psychol. 3:1766. doi: 10.5964/jspp.v3i1.564
The online video platform provides an ample launching pad on which to encourage participation in visual narratives that embrace diverse perspectives and engage the whole of the public in the story of science. Let's use it as an interactive bridge across oceans, cultures and demographics, connecting people across the globe and investing them in the stories that tap into our humanity-and thus, the issues. Only when we share in a collective narrative of science, will its story be complete.

\section{AUTHOR'S NOTE}

As an ocean documentary filmmaker and scholar, my work emerges at the intersection of marine science, history, media and culture. When these seemingly disparate camps are allowed to mingle, a potent alchemy results. Drawing on my two decades of experience writing and producing science and natural history films for major broadcasters and using my establishment of the non-profit organization, Ocean Media Institute as a launching point, I make the case for greater inclusivity in the production of online media in order to create a more complete story of ocean science. In today's rapidly expanding media landscape, I propose that we seize the opportunity to disrupt the notion of narrative ownership and turn instead to a collective narrative that embraces diverse perspectives and participation in the story of the ocean. It is my view that our own work can only be validated when we are challenged, questioned, and pushed by each other to step outside the "established" perimeters of our study. Only from that vantage, will we be permitted the freedom to think deeply, and perhaps differently, about how our methods affect our work and thus, our legacy as science communicators.

\section{AUTHOR CONTRIBUTIONS}

The author confirms being the sole contributor of this work and has approved it for publication.

\section{FUNDING}

The Ocean Media Institute receives support via private donations and has received a grant from the National Geographic Society (\#NGS-404E-18). The Center for Science Communication at the University of Otago has paid for open access publishing fees.

\section{ACKNOWLEDGMENTS}

A depth of gratitude to all the participants of our I am Ocean initiative as well as my indefatigable colleague and co-director, Jeff Reed for his creative guidance. Many thanks also to the Board of Directors of the Ocean Media Institute and to the University of Otago for supporting my ongoing research.

Alexander, S. M., Provencher, J. F., Henri, D. A., Taylor, J. J., and Cooke, S. J. (2019). Bridging Indigenous and science-based knowledge in coastal and marine research, monitoring, and management in Canada. Environmental Evidence 8, 36. doi: 10.1186/s13750-0190181-3 
Arismendi, I., and Penaluna, B. E. (2016). Examining diversity inequities in fisheries science: a call to action. Bioscience 66, 584-591. doi: 10.1093/biosci/biw041

Avraamidou, L., and Osborne, J. (2009). The role of narrative in communicating science. Int. J. Sci. Educ. 31, 1683-1707. doi: 10.1080/09500690802380695

Bucchi, M. (2016). "Editorial," Public Understanding of Science. London: Sage Publishing, 264-268.

Dahlstrom, M. F. (2014). Using narratives and storytelling to communicate science with nonexpert audiences. Proc. Natl. Acad. Sci. U.S.A. 111, 13614-13620. doi: $10.1073 /$ pnas. 1320645111

De Fina, A., and Georgakopoulou, A. (2011). "Narrative power, authority and ownership," in Narrative: Discourse and Sociolinguistic Perspectives (Cambridge: Cambridge University Press) 125-154.

Gill, J. (2018). Decolonizing literature and science. Configurations 26, 283-288. doi: $10.1353 /$ con.2018.0023

Green, S. J., Armstrong, J., Bogan, M., Darling, E., Kross, S., Rochman, C. M., et al. (2015). Conservation needs diverse values, approaches and practitioners. Conserv. Lett. 8, 385-387. doi: 10.1111/conl.12204

Hayden, T., and Check Hayden, E. (2018). Science Journalism's unlikely golden age. Front. Commun. 2:24. doi: 10.3389/fcomm.2017.00024

Hipkins, R., Bolstad, R., Boyd, S., and McDowall, S. (2014). Key Competencies for the Future. Wellington: NZCER Press, 14-15.

McCoy, D. L., and Rodricks, D. J. (2015). Critical race theory in higher education: 20 years of theoretical and research innovations. ASHE High. Educ. Rep. 41, 1-117. doi: 10.1002/aehe.20021

Mcleod, E., Arora-Jonsson, S., Masuda, Y., Bruton-Adams, M., Emaurois, C. O., Gorong, B., et al. (2018). Raising the voices of Pacific Island women to inform climate adaptation policies. Mar. Policy 93, 178-185. doi: 10.1016/j.marpol.2018.03.011

Nash, K. (2012). Telling stories: the narrative study of documentary ethics. New Rev. Film Televis. Stud. 10, 318-331. doi: 10.1080/17400309.2012. 693765

Norris, S. P., Guilbert, S. M., Smith, M. L., Hakimelahi, S., and Phillips, L. M. (2005). A theoretical framework for narrative explanation in science. Sci. Educ. 89, 535-563. doi: 10.1002/sce.20063
Peterson, B. L., and Garner, J. T. (2019). Tensions of narrative ownership: exploring the rise of (counter) narratives during the fall of Mars Hill Church. Western J. Commun. 83, 1-19. doi: 10.1080/10570314.2018. 1462525

Rowe, G. (2017). As quoted by Tim Fontaine in "Let Our Indigenous Voice be Heard," CBC News. Available online at: http://www.cbc.ca/news/indigenous/ indigenous-scientists-march-for-science-2017-1.4077662 (accessed June 15, 2020).

Rutherford, A. (2004). Negotiating indigenous documentary: storytelling, audience and cultural sensibility; Anne Rutherford Interviews Darlene Johnson. Metro Magazine: Media and Education Magazine 139, 56-61. Available online at: https://search.informit.com.au/fullText; dn= 833103870863018;res=IELAPA (accessed 14 June, 2020).

Smith, M. S. (2017). "10 disciplinary silences: race, indigeneity, and gender in the social sciences," in The Equity Myth: Racialization and Indigeneity at Canadian Universities (Vancouver, BC: UBC Press), 392.

Smith, N. S., Côté I. M., Martinez-Estevez, L., Hind-Ozan, E. J., Quiros, A. L., Johnson, N., et al. (2017). Diversity and inclusion in conservation: a proposal for a marine diversity network. Front. Mar. Sci. 4:234. doi: 10.3389/fmars.2017.00234

Tallis, H., and Lubchenco, J. (2014). Working together: a call for inclusive conservation. Nature 515, 27-28. doi: 10.1038/515027a

Taylor, D. (2014). The State of Diversity in Environmental Organizations. Ann Arbor, MI: University of Michigan.

Conflict of Interest: GS is the founder of the Ocean Media Institute, though she personally receives no commercial or financial benefit from this relationship.

Copyright (c) 2020 Savoie. This is an open-access article distributed under the terms of the Creative Commons Attribution License (CC BY). The use, distribution or reproduction in other forums is permitted, provided the original author(s) and the copyright owner(s) are credited and that the original publication in this journal is cited, in accordance with accepted academic practice. No use, distribution or reproduction is permitted which does not comply with these terms. 